\title{
Hispanic Carpenter Dies After Falling From Homemade Platform
}

\author{
Incident Number: 07KY008
}

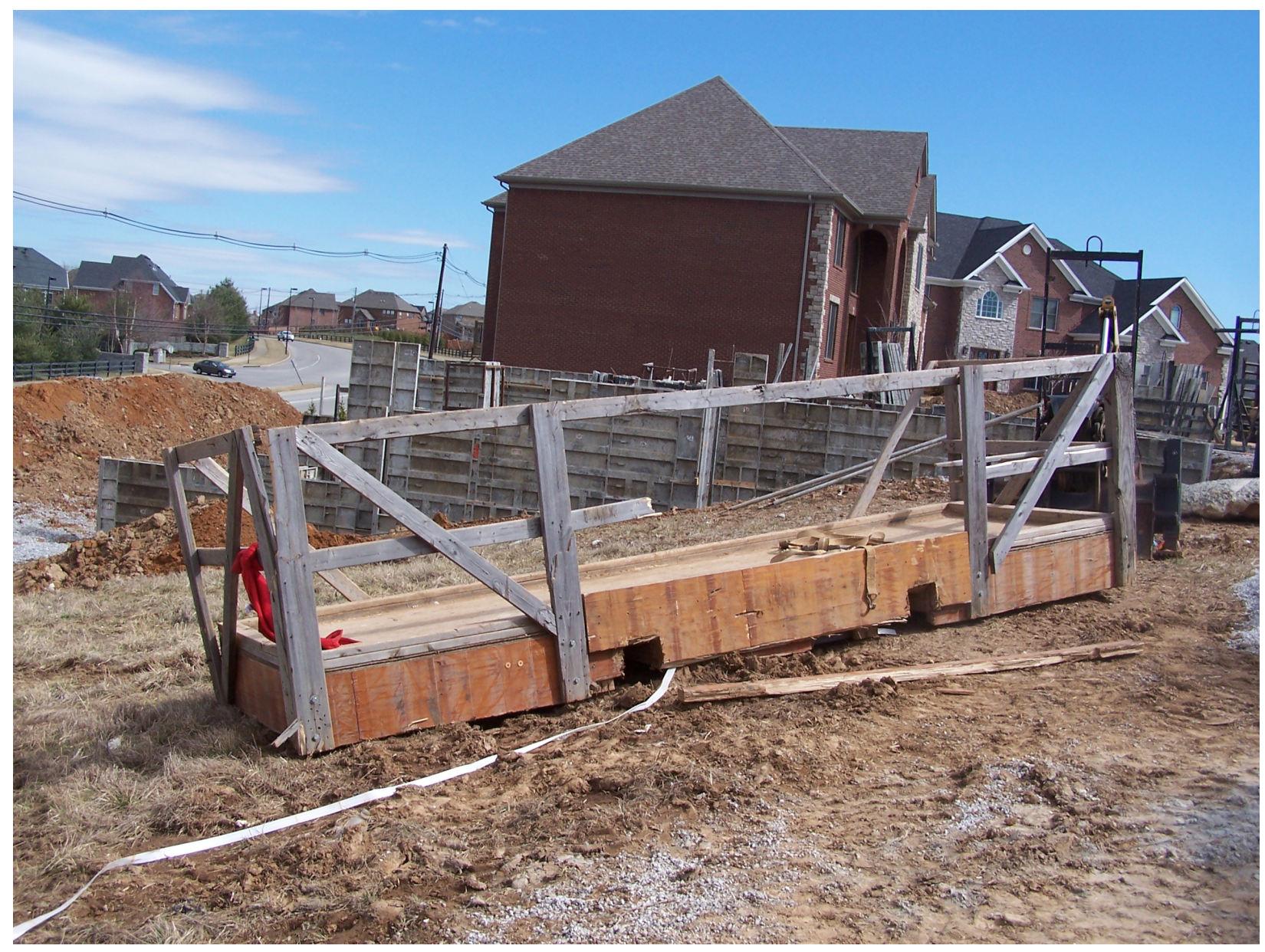

Picture of homemade platform involved in this incident. Notice railing and cleats.

Kentucky Fatality Assessment and Control Evaluation Progran Kentucky Injury Prevention and Research Center 333 Waller Avenue

Suite 206

Lexington, Kentucky 40504

Phone: 859-323-2981

Fax: 859-257-3909

www.kiprc.uky.edu

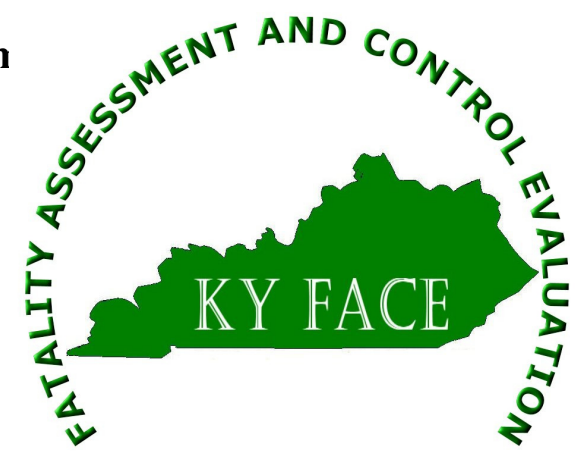




\section{Kentucky Fatality Assessment and Control Evaluation (FACE) Program Incident Number: $\quad 07 K Y 008$ Release Date: January 22, 2008 Subject: Hispanic Carpenter Dies After Falling From Homemade Platform}

\section{Summary}

In the Spring of 2007, a 32-year-old Hispanic male carpenter (decedent) died when he fell from a homemade platform (extended approximately seven feet in the air) after it detached from a telehandler (forklift). The decedent and two other carpenters were framing a new construction, single-family residence located on a hillside which was rough and steep. The three carpenters were framing the wall at the rear corner of the house which was high because of the sloping terrain. To reach the area, the crew decided to use a homemade platform as a makeshift scaffold. A fourth worker operated a rough-terrain forklift and elevated the platform with the three carpenters holding the wall to be framed up in the air. The forklift operator lifted the unsecured platform and at approximately seven feet in the air, the platform fell off the forks. Two of the carpenters fell off the platform, which fell on the edge of the foundation above the men's heads. The decedent fell off the left end of the platform which struck him in the head. Emergency medical services were summoned to the scene. Upon their arrival they found the other two carpenters who had fallen together alive and requiring medical attention. They were transported to a nearby hospital and later released. Emergency medical service personnel found the third carpenter to be without vital signs and contacted the local coroner who arrived and declared the carpenter dead at the scene.

To prevent future occurrences of similar incidents, the following recommendations have been made:

Recommendation No. 1: Companies should not attempt to build any "homemade" type personnel platform for a forklift, all personnel platforms must comply with ANSI / ASME standards and the OSHA regulations.

Recommendation No. 2: Those who use a personnel platform on a rough terrain forklift must use approved fall-protective equipment.

Recommendation No. 3: Scaffolding should be used in difficult-to-reach framing locations.

Recommendation No. 4: Personnel should not be transported by material hoists.

Recommendation No. 5: Forklift operators should be trained by a competent person to operate forklifts correctly and safely.

Recommendation No. 6: Employers with multicultural workers should design safety training in languages suited for the company workforce. 
Recommendation No. 7: General contractors should ensure through contract language that all subcontractors implement appropriate safety and health programs and training specific to the work to be performed.

Recommendation No. 8: Small business owners should institute and enforce drug testing policies.

\section{Background}

The privately owned construction company where the deceased was employed had been in business for approximately four to five years. The company specialized in framing and carpentry and employed eight workers. The decedent had been employed by the company for four years as a carpenter. According to an employee, the decedent had 10 years of constructionrelated work experience. The company conducted safety toolbox talks with their employees.

\section{Investigation}

In the Spring of 2007, the Kentucky Fatality Assessment \& Control Evaluation program was notified by a construction professional of a fatality involving a Hispanic construction worker. The FACE team went to the scene, took photographs and interviewed an employee of the construction company where the Hispanic was employed. The coroner's and the Kentucky Occupational Safety and Health reports of the incident were obtained.

On the morning of the fatality, three Hispanic carpenters were framing a new, multi-story, single-family house. The terrain of the building lot was hilly, steep and rough with the backside of the lower level of the house open out of the slope. At approximately 7:30 AM, the three men were to erect a section of wall above the foundation of the lower level in the back left side of the house. According to an employee, the carpenters typically would have used ladders to reach the area to be framed. Because the terrain was rough and steep, and the work area was higher than the ladders could reach, it was decided to use a homemade materials platform to perform the task. The platform was constructed of wood, had railing on three sides with cleats on the bottom of the long side with railing. The cleats had been inserted on the railing side for stability when lifted. The operator of the forklift had inserted the forks under the long side of the platform without the cleats. This caused the platform to rest on top of the forks and be more unstable. The platform was not secured to the forklift.

The forklift operator elevated the three carpenters on the platform while they were holding the wall to be set in place. When the platform reached approximately seven feet high, it slipped off the forks and tumbled the three men to the ground. Two of the carpenters fell close to the house under the right side of the platform which fell on the edge of the foundation of the house. The third carpenter was struck by the left side of the platform as it slid to the ground. One of the workers called emergency medical services. The fire department and police arrived. Upon their arrival, they found the two carpenters alive and the third carpenter without vital signs. Both of the injured carpenters were transported to a nearby hospital where they were treated for their injuries. The local coroner arrived and declared the third carpenter dead at the scene. 
According to the coroner's report, wind may have also contributed to the incident. Ambient temperatures that day ranged from 24 degrees Fahrenheit to 54 degrees Fahrenheit.

\section{Cause of Death}

The death certificate states the cause of death was due to "blunt impact of head with skull fractures and evisceration of brain". Toxicology results detected cocaine, cocaethylene, and a presumptive presence of cocaine metabolites, and benzodiazepine.

\section{Recommendations and Discussions}

Recommendation No. 1: Companies should not attempt to build any "homemade" type personnel platform for a forklift, $\backslash$; all personnel platforms must comply with ANSI / ASME standards and the OSHA regulations.

ASME standards allow a company to construct and attach a personnel platform to a rough terrain forklift. There are rigorous guidelines for this, and it is, therefore, preferred that individuals consult with the forklift manufacturer for assistance, or better, purchase a factory-made and approved personnel platform designed for their particular machine.

Requirements for an approved personnel platform include proper size, approved guard rails, rated anchor points for attachment of lifelines, and a safe method to secure the platform to the forklift. OSHA frequently writes citations for inadequate / home-made personnel platforms, deferring to the restrictions written into machine operator's manuals, which usually forbid using a homemade personnel platform on a forklift. Usually, the manufacturer's operator manual provides some guidance on this issue, therefore, companies desiring a personnel platform for a forklift should to study their options carefully. In addition, personnel platforms must be securely anchored to the forks of a machine.

Recommendation No. 2: Those who use a personnel platform on a rough terrain forklift must use approved fall-protective equipment.

Approved equipment in this case would be a full body harness, and lifeline which does not permit a fall of more than six feet. This ruling applies to all extended boom machines, for they have the potential of bouncing a worker up and off the platform, even if the platform is equipped with permanently-mounted guard rails. Exceptions to this rule are for scissor lifts, which have permanently attached guard rails. These machines use hydraulic-powered mechanical linkages to slowly raise and lower the work platform, minimizing the potential to bounce a worker up and off of the platform. In this case, the victim was not wearing any type of fall protection, and was working near an unprotected edge of the personnel platform.

Recommendation No. 3: Scaffolding should be used in difficult-to-reach framing locations.

Construction workers should use appropriate tools to perform tasks. In this case, properly erected scaffolding would have provided an appropriate, safe and secure platform for the carpenters to frame the wall of the house. Some common types of scaffolding the workers could have used are system, or tubular. Scaffolding should only be erected under the guidance of a 
competent person. The Occupational Safety and Health Administration defines a competent person as "one who is capable of identifying existing and predictable hazards in the surroundings or working conditions which are unsanitary, hazardous, or dangerous to employees, and who has authorization to take prompt corrective measure to eliminate them". 29 CFR 1926.451(f)(7) states the competent person is "to select and direct employees who erect, dismantle, move, or alter scaffolds." The terrain on the job site involved in this incident was steep. The roughterrain forklift had to be positioned on the ground at an angle to the house. This would have made elevating the platform on the level difficult. Scaffolding should have been erected so the carpenters could reach the area to be framed and work from a secure level platform. Also, 29 CFR 1926.451(f)(12) states the competent person is "to determine if it is safe for employees to work on or from a scaffold during storms or high winds and to ensure that a personal fall arrest system or wind screens protect these employees. (Note: Windscreens should not be used unless the scaffold is secured against the anticipated wind forces imposed.)"

Recommendation No. 4: Personnel should not be transported by material hoists.

Employees should be trained to follow OSHA Standard 29 CFR 1926.552(b)(1)(ii) which states "no person shall be allowed to ride on material hoists except for the purposes of inspection and maintenance". Due to the terrain of the ground and the location of the area of the house to be framed, the material hoist was used to elevate the three workers and the wall to erect and secure it on the foundation. Appropriate scaffolding would have provided more solid footing, and would have allowed the workers more room to maneuver the wall and secure it safely into place.

Recommendation No. 5: Forklift operators should be trained by a competent person to operate forklifts correctly and safely.

It is unknown if the operator of the forklift had been properly trained to operate the forklift used in this incident. 29 CFR 1926.602(d) refers to CFR 1910.178(1): Powered industrial trucks, operator training that states, "the employer shall ensure that each powered industrial truck operator is competent to operate a powered industrial truck safely, as demonstrated by the successful completion of the training and evaluation specified in this paragraph (1). Sections which specifically apply to this incident are: 29 CFR 1910.178(1)(3)(i)(G) that states the operator should understand fork and attachment adaptation, operation and use limitation of the forklift. Forklift operators should be trained to understand the importance of using cleats and the stability they provide when elevating platforms. The cleats were located on the outside of the platform with the rail so that when elevated, the open side of the platform was away from the forklift. Typically this platform was used to hoist building materials to/from the ground. In this incident, the platform was lifted from the opposite side so the railing was away from the forklift. This created the illusion that the three men had a railing to protect them from falling off the platform. 29 CFR 1910.178(1)(3)(ii)(A) and 29 CFR 1910.178(1)(3)(ii)(G) state the operator should understand the "surface conditions where the forklift will be operated" and "ramps and other sloped surfaces that could affect the vehicle's stability", respectively. Rough terrain forklift operators should be trained to recognize hazardous terrain which would include grade, and roughness of terrain. 29 CFR 1910.178(1)(3)(ii)(B) states that the operator should understand the "composition of the loads to be carried and load stability". 
Forklift operators should be trained to recognize proper weight distribution of the loads they are elevating with the forks. This would include recognition of unstable weight at the end of the forks of the forklift and the hazardous condition this creates. Forks should be opened as wide as possible to provide stability to the platform. Forklift operators should be trained to recognize the hazards of not securing personnel platforms being elevated by forklifts. 29 CFR 1926.602(1)(viii)(A) states that when personnel are being elevated on a platform, it should be "firmly secured to the lifting carriage and/or forks". Therefore, forklift operators should be trained to ensure platforms being used to elevate workers are properly secured to the mast. Also, the platform should be equipped with an appropriate guardrail with a locking gate. Elevated personnel should have controls on the platform that allow them to shut off power to the forklift. And, the forklift operator should not leave the controls of the forklift so that the elevated personnel can give instructions to the operator.

Recommendation No. 6: Employers with multicultural workers should design safety training in languages suited for the company workforce.

According to a company employee, toolbox talks were conducted. It is unclear if the subject matter covered all pertinent aspects of the tasks the employees were to perform, or if they were held on a regular basis. Employers should conduct safety training so that it is understood by all employees regardless of their ethnicity and education level. This training should include worker rights, how to recognize and avoid hazardous situations, and task-specific safety rules (such as wearing goggles and appropriate gloves). The competent person on the job site should be able to communicate with non-English speaking workers in a manner that ensures all parties understand the safety issues and how to work safely. Non-English speaking workers should have avenues of clear and concise communication to notify supervisors of hazardous situations that occur on the job site.

Recommendation No. 7: General contractors should ensure through contract language that all subcontractors implement appropriate safety and health programs and training specific to the work to be performed.

General contractors should ensure that all subcontractors have safety and health training programs in place that address the tasks their workers are assigned to perform through contract language that requires all subcontractors to identify how they intend to implement a site-specific safety and health program before the initiation of work. The subcontractors' contract should contain clear and concise language describing which party is responsible for a given safety or health issue. Any differences should be negotiated before work begins. Once the provision for these responsibilities has been established, the respective parties should ensure that the provisions of the contract regarding safety and heath are upheld through regular inspections of the work site.

Recommendation No. 8: Small business owners should institute and enforce drug testing policies.

Small business owners can get assistance to develop drug policies from the Associated General Contractors of America Association (AGC) which has signed an alliance with OSHA, MSHA 
and the Working Partners for an Alcohol- and Drug-free Workplace Program (Office of the Assistant Secretary for Policy Working Partners). This program provides "the construction industry with information, guidance, and access to training resources that will help them understand the benefits of drug-free workplace programs and protect employees' health and safety. The Alliance particularly focuses on educating workers on safety and productivity hazards created by the abuse of alcohol and other drugs in the workplace."

\section{Keywords}

Homemade platform

Rough terrain forklift

\section{References}

1) $\quad 29 \mathrm{CFR} 1926.451(\mathrm{f})(7)$

2) 29 CFR 1926.552(b)(1)(ii)

3) 29 CFR 1926.602(d)

4) 29 CFR 1910.178(1)

5) United States Department of Labor, Occupational Safety and Health Administration, "Drug Free Workplace Alliance" http://www.osha.gov/dcsp/alliances/drug_free/drug_free.html

6) United States Department of Labor, Occupational Safety and Health Administration, "A Guide To Scaffold Use In The Construction Industry”, OSHA 31502002 (Revised) http://www.osha.gov/Publications/OSHA3150/osha3150.html

7) National Institute of Occupational Safety and Health, Fatality Assessment and Control Evaluation Program, "Hispanic Construction Laborer Dies and Two Coworkers Are Injured After Falling 10 Feet From an Unsecured Box on the Forks of a Forklift - North Carolina" http://www.cdc.gov/niosh/face/In-house/full200305.html

8) American National Standards Institute, American National Standard for Manually Propelled Elevating Ariel Platforms, ANSI/SIA A92.3-2006, http://webstore.ansi.org/RecordDetail.aspx?sku=ANSI/SIA\%20A92.3-2006

9) American National Standards Institute, ANSI B56.6-2002[8.24.1(b)]

10) Rental Equipment Register, "Raising the Bar on Training", http://rermag.com/mag/equipment_raising_bar_training/index.html

11) Code of Federal Regulations 2001 edition. 29 CFR 1926.602(c)(1)(viii). U.S. Printing Office, Office of the Federal Register, Washington, D.C. 
12) Swartz G. [1999]. Forklift safety-a practical guide to preventing powered industrial truck incidents and injuries. 2nd ed. Rockville, MD: Government Institutes, A Division of ABS Group Inc.

13) NIOSH [1999]. NIOSH Alert: preventing injuries and death of workers who operate or work near forklifts. Cincinnati, OH: U.S. Department of Health and Human Services, Public Health Service, DHHS (NIOSH) Publication No. 2001-109.

14) Equipment Manufacturers Institute. Rough terrain forklift. Chicago: Illinois. Form \#RT85-2.

\section{Acknowledgements}

Business owner

Construction safety specialist

Kentucky Occupational Safety Compliance Officer

Local coroner

National Institute of Safety and Health Specialist

The Kentucky Fatality Assessment \& Control Evaluation Program (FACE) is funded by a grant from the Centers for Disease Control and the National Institute of Safety and Health. The purpose of FACE is to aid in the research and prevention of occupational fatalities by evaluating events leading to, during, and after a work related fatality. Recommendations are made to help employers and employees to have a safer work environment. For more information about FACE and KIPRC, please visit our website at: www.kiprc.uky.edu 


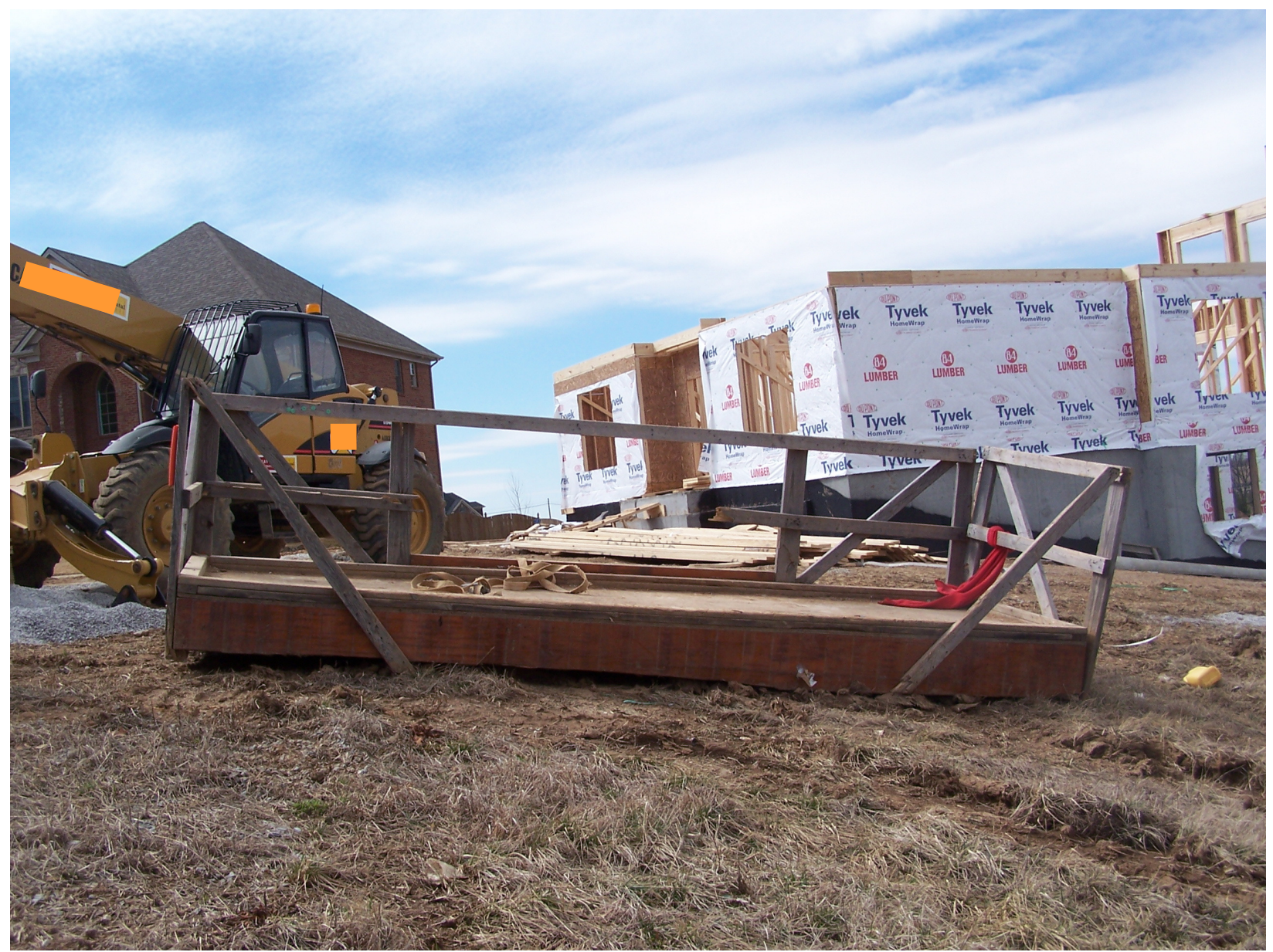

Picture of side used to lift homemade platform. Notice there are no cleats for forks on this side. 


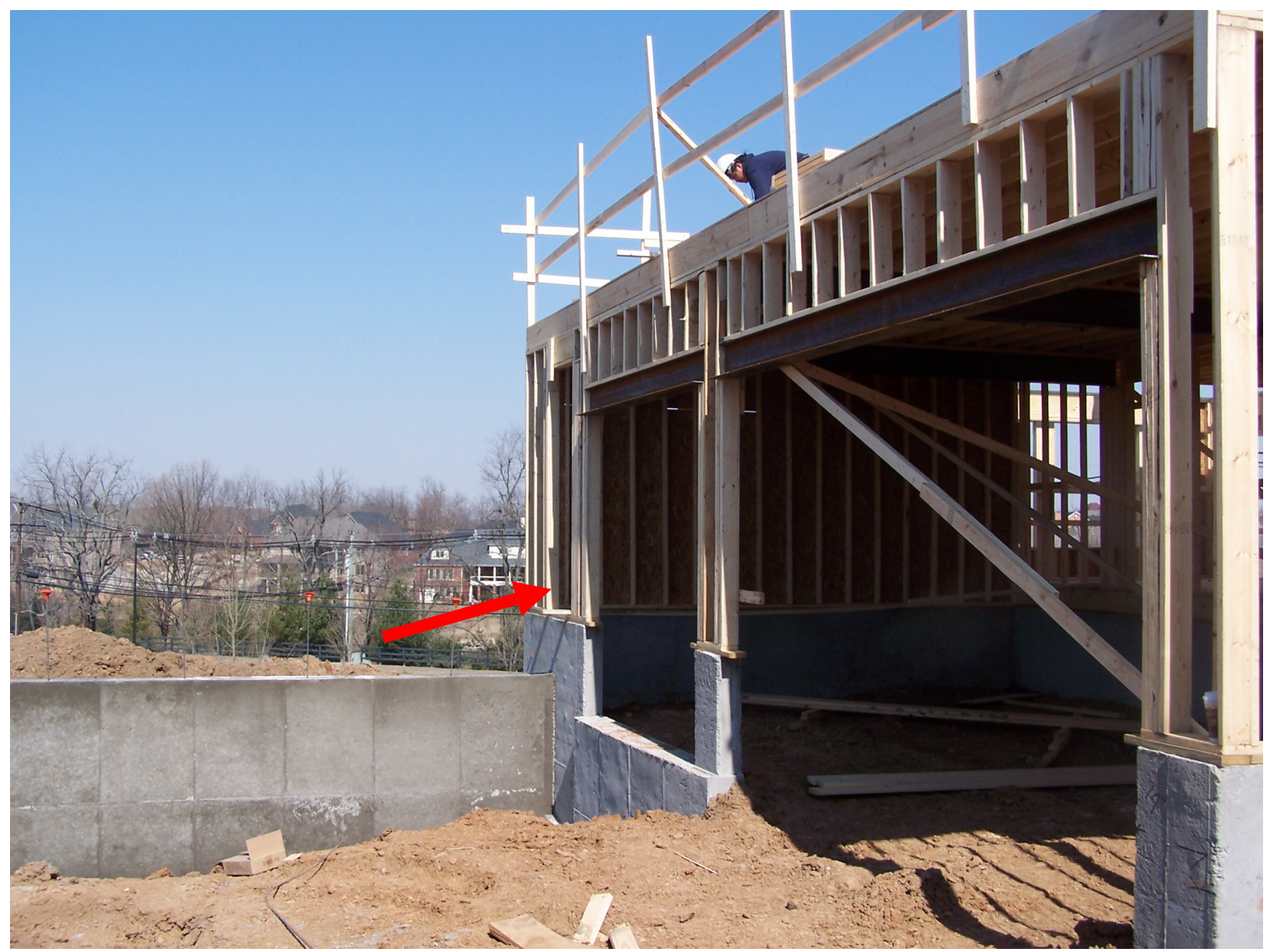

Corner of house where carpenters were to erect the wall. The concrete wall was not there at time of incident. 